\title{
Success! Facilitating Choice for Renal Patients in The Tropics With Central Venous Lines to Maintain The Integrity of Their Dressings While Attending to Personal Hygiene: A Multi-Phase Study
}

Wendy Smyth ( $\nabla$ wendy.smyth@health.qld.gov.au )

Townsville Hospital and Health Service

Joleen McArdle

Townsville Renal Service, Townsville

Kristin Wicking

James Cook University, Townsville

Kimberley Quayle

Townsville Renal Service, Townsville

Cate Nagle

James Cook University, Townsville

\section{Research Article}

Keywords: Behaviour change, central venous catheter, hygiene, wound dressing care

Posted Date: April 15th, 2021

DOI: https://doi.org/10.21203/rs.3.rs-400131/v1

License: (c) (1) This work is licensed under a Creative Commons Attribution 4.0 International License.

Read Full License 


\section{Abstract}

Aim:

To explore individual patients' choices in personal hygiene, while maintaining the integrity of catheter exit site dressings between dialysis sessions.

\section{Background:}

For patients undergoing haemodialysis via a central venous catheter (CVC), infection is a major lifelimiting risk. Meticulous attention to keeping the exit site dressing clean and dry is an essential defence in preventing infections. It is difficult to maintain the integrity of water-resistant dressings in tropical environments.

\section{Design:}

A three-phase exploratory study was conducted in a northern Australian Renal Service.

\section{Methods:}

Phase One employed a cross-sectional survey of nurses on the acceptability and feasibility of two hygiene options: bathing wipes and a waterproof dressing cover. Phase Two used conversational-style interviews with patients about their hygiene preferences, how they endeavoured to keep their dressings dry, and impressions regarding the provided options. Phase Three was a series of case studies of patients trialling the provided options. The STROBE checklist was used.

\section{Results:}

Phase 1: Nurses $(n=37)$ considered both options acceptable and feasible, noting some practical concerns related to their use.

Phase 2: Patients $(n=27)$ described hygiene preferences and difficulties they encountered with keeping dressings dry. They were enthusiastic about trying the proposed options.

Phase 3: Patients $(n=22)$ appreciated being able to shower without wetting their exit site dressings. Individuals were inventive in modifying the application and use of the waterproof cover according to their body shape and exit site location. Although participants liked both options, the waterproof covering was most popular and most frequently used. Intactness of the dressings was $83 \%$ during the trial; there were no CVC-associated infections during the study.

\section{Conclusion:}

Assisting patients keep their dressings dry and intact during personal hygiene in a tropical environment promoted dignity and autonomy. 


\section{Implications for clinical practice:}

Patients demonstrated their willingness to undertake a more active role in their dressing care.

\section{What Does This Paper Contribute To The Wider Global Clinical Community?}

- The study design facilitated open discussion about personal hygiene preferences and practices in a culturally-safe manner

- Patients embraced the opportunity afforded by the two products trialled, to undertake personal hygiene according to their personal preferences.

- The opportunity to perform personal hygiene according to their individual preferences removes one lifestyle modification faced by patients who undergo haemodialysis via a central venous catheter.

\section{Introduction}

Imagine having to go to the same place at the same time three days every week for the rest of your life for haemodialysis. Added to this, you may have had to relocate to a regional city, hundreds of kilometres from your home, and live in shared accommodation with little family support. Now add that you have a central venous line (CVC) in situ with a dressing over the exit site. You live in a tropical climate (that is, it is hot and humid), and would like to attend to your hygiene according to your own preferences. Nurses tell you that with a CVC you should bathe rather than take a shower, but your bathroom only has a shower, and in any case, you feel cleaner after showering. You know that you need to keep your dressing dry and intact as a protection against infection. But how? This is the dilemma facing up to one-third of the patients undergoing haemodialysis at a northern Australian Renal Service.

\section{Background}

Although arterio-venous fistulas have been the preferred haemodialysis vascular access option, there are many reasons for CVC lines, including late referrals, patients' preferences and patients' fear of pain associated with needling of fistulas (1). Patients' preferences may mean that CVC access becomes longterm, even if they are aware that CVC exit sites are more likely to lead to systemic infections.

The risk of bacteraemia of hospitalised patients is very real, and the consequences of such infections can be serious for the patient and costly to the organisation. Patients with invasive devices such as CVCs and those who have multiple morbidities, such as those with end-stage renal disease on haemodialysis, have a greater infection risk than patients without such factors (2). Whilst cardiovascular disease and withdrawal from treatment are now the major causes of death among Australian and New Zealand patients on haemodialysis, infection was the major cause of death for 170 Australian and New Zealand patients in 2018 (3). It is difficult to definitively quantify the cost associated with catheter-related 
bloodstream infections because of the variation between countries and health services, but costs have been quoted ranging from approximately $\$ 3,500$ US to almost $\$ 70,000$ US per episode (4).

Meticulous attention to CVC exit site care is essential to prevent bacterial contamination (5). The first line of defence against infection of a CVC exit site is a dry, intact dressing (6). A crossover randomised controlled trial of an opaque dressing and a transparent dressing conducted in the [name of hospital blinded for review] Renal Service found that both dressings remained fully intact between dialysis sessions less than $70 \%$ of the time (6). Nurses are keenly aware of the risks of acquiring infections from wet dressings and the risks associated with patients changing their own dressings (1). There are no standardised approaches to teaching patients the principles of managing their CVC exit site dressings, such as how to keep the dressings dry, how to replace dressings that have loosened between dialysis sessions, how to replace dressings that have become wet during showering, or how to care for exit sites in 'difficult to reach' areas. Sometimes, patients are given extra dressings to place over an exit-site dressing when they shower, but this does not mean that the dressing beneath stays dry. Such practices also do not encourage self-care by the patient; nor is this practice evidence-based (7).

Although patients have been able to reduce their risk of CVC-related infections by covering their line when they have a shower (1), wound dressings are water-resistant rather than waterproof. It is reasonable to expect that patients will want to shower or bathe, particularly in a tropical climate. The written information provided to patients with CVCs advised against showering and suggested that bathing was the best option (8). However, this may not be what an individual patient wants or is able to perform safely; indeed, they may not even have access to a bathtub. Patients requiring haemodialysis need to make many adaptations to their lifestyle - such as activity, diet and fluids. Having a CVC imposes additional adaptations related to care of the catheter exit site. This level of adaptation can be disempowering; supporting patients to attend to their personal hygiene as they wish may give back some control to the individual patient.

It has been argued that adoption of a person-centred care approach, that "balances research-based evidence with patient circumstances and preferences may be preferable to the current strategy of encouraging AVF [arterio-venous fistula] as the primary vascular access option, regardless of patient choice" $(1$, p.26). In a study of self-care dialysis patients, the support of nursing staff was considered essential to their ongoing self-management (9). Discussions about personal hygiene practices can be quite confronting and need to be non-judgemental and culturally-sensitive. Patients attending one northern Australia Renal Service live in a range of accommodation types including shared or temporary accommodation and hostels (10), and individuals attend to their hygiene in many ways. There are products that can be used instead of showering/bathing (e.g. bath wipes) and there are waterproof products that can be placed over CVC exit sites to protect the dressings during showering/bathing. Understanding more regarding patient hygiene preferences is critical to providing patient-centred care and promoting patients' dignity. 


\section{Study aim}

The aim of this study was to explore patients' choices in personal hygiene while maintaining the integrity of their CVC exit site dressings between dialysis sessions. This aim was achieved by:

- Identifying enablers and barriers to patients using different options for their personal hygiene, as perceived by the nurses working within the XXXX Renal Service;

- Ascertaining feedback from patients with a CVC in situ about their preferences regarding showering and personal hygiene between dialysis sessions;

- Evaluating participants' experiences with being supported to use different options to assist with their personal hygiene between dialysis sessions

\section{Methods}

\section{Study design}

This was a three-phase exploratory study employing different methods in each phase. Phase 1 was a cross-sectional survey design of nurse participants. Phase 2 used a qualitative narrative design for the initial patient interviews, and Phase 3 used a multiple case study (qualitative) approach $(11,12)$ for the patient participants. The findings in Phases 1 and 2 informed Phase 3 participant selection.

There are several frameworks for considering behaviour change (13). This study was guided by the ' $\mathrm{COM}$ B system' framework which has three essential components: capability, opportunity and motivation for the behaviour). Therefore the person must be capable (psychologically and physically) of the behaviour, and be motivated to change, along with the opportunity for the desired behaviour to occur (13). Each of the three factors (capability, opportunity, motivation) can influence the other. This framework guided the design, implementation, analysis and interpretation of results.

\section{Setting}

The setting for all three phases was a Renal Service in a regional city within the tropical region of northern Australia. The sample, recruitment, outcome measures, data collection, and data analysis varied by Phases, and will be discussed separately for each Phase.

\section{Participants and Recruitment}

Phase 1: All nurses ( $\mathrm{N}=63)$ working in the Renal Service at the time of survey distribution, were invited to complete an anonymous electronic questionnaire, which was distributed in late August 2018. Two global reminder emails were sent.

Phase 2: All patients $(\mathrm{N}=27)$ undergoing haemodialysis via a $\mathrm{CVC}$, at the time of data collection toward the end of 2018, were invited to participate in a conversational style, semi-structured interview about their 
hygiene preferences (such as frequency, bath/shower), and their initial thoughts about two hygiene products - bath wipes and a waterproof dressing cover (the interventions).

Phase 3: Patients with a cuffed tunnelled CVC, assessed by nursing staff to have the dexterity to use the different options for protecting the integrity of their CVC dressing while they showered/bathed, were invited to participate in Phase 3. Patients with a previous skin reaction to the products being trialled, and patients with an exit site or CVC-related infection at the time of recruitment were excluded from participating. Anticipated sample size was approximately 20. Progressive recruitment to this phase began in January 2019.

\section{The interventions}

As part of the study, two products were made available to participants. The first was a packet of eight, disposable bath wipes ('Bath in bed wipes', Reynard Health Supplies), each measuring $33 \mathrm{~cm}$ by $23 \mathrm{~cm}$, and costing less than \$1 AUD per pack. The bath wipes could be heated and/or cooled. The other product was a waterproof cover ('Keep Dri Dressing', Sutherland Medical Pty Ltd) that was placed over the exit site dressing and removed and disposed of after showering. The cover was available in two sizes, $23 \mathrm{~cm}$ by $17 \mathrm{~cm}$ and $26 \mathrm{~cm}$ by $23 \mathrm{~cm}$ depending on patient preference and were available in packs of five or 25 . Each individual cover cost a little over \$1 AUD.

\section{Data Collection}

\section{Phase 1:}

A questionnaire was developed by the research team on the Qualtrics platform, with iterative revisions, after piloting with nurses who would not be included in the final sample. Photographs and descriptions of each product were included within the questionnaire to stimulate recognition if they had been used previously, and to promote a full understanding of the proposed products' features. Closed-ended questions regarding acceptability and feasibility were also included.

\section{Phase 2:}

An informal interview guide was developed with questions that sought to respectfully elicit honest and open discussions about actual hygiene practices in a non-judgmental, plain English style. The conversational interviewing style was congruent with the 'yarning' method of Indigenous research (14). These conversations were not audio recorded, but rather the interviewer took handwritten notes. During these conversations, the participants were shown the products available (the intervention).

\section{Phase 3:}

Data were collected for each participant over a six-week period, during which they could choose which product/s they would like to try. At each dialysis session, the CVC exit site was inspected by the renal service nurses for dressing intactness and dryness. Intactness was defined as "all four edges of the 
dressing remaining adhered to the skin" (Hughes et al., 2011). At least weekly, a research nurse used an informal 'yarning' conversational approach as in Phase 2, to talk with the participant about how they attended to their hygiene between dialysis sessions, whether they had used either or both products provided, and whether their dressing had become wet while washing themselves.

\section{Data analysis}

Descriptive statistics (frequencies, percentages, medians, modes) were used to summarise responses to the Likert-style questionnaire responses. Responses to open-ended questions were analysed using content analysis (15) with the codes derived from the objectives of the study. One researcher (XX) led the coding of the data after readings of responses and then emerging themes were identified. All team embers then reviewed and discussed the analysis. Exemplars of patient stories are presented to highlight emergent themes.

\section{Ethical considerations}

Minimal research about CVC line exit site care has been undertaken in a tropical setting or with Aboriginal and/or Torres Strait Islander Peoples. Most of the participants in this study were likely to be Aboriginal and/or Torres Strait Islander, given their over-representation within the Australian haemodialysis population and within this Renal Service. It was essential for the research to be culturally appropriate and incorporate the values and principles underpinning research with Aboriginal and Torres Strait Islander Peoples (16). As part of the research ethics approval process, the researchers met with the Health Service's Aboriginal and Torres Strait Islander Health Leadership Advisory Council to ensure that the study met these values, and guidance was provided with respect to wording of the participant information sheets, consent forms, and interview guides. The Health Service's Human Research Ethics Committee approved the study (HREC/18/QTHS/46).

\section{Results}

\section{Phase One}

The link to the questionnaire was emailed to 63 nurses working within the Renal Service; 47 nurses consented to participate and 37 questionnaires were completed, giving a response rate of $58.7 \%(37 / 63)$. The questions focused on the acceptability, feasibility, benefits and barriers to the use of the two intervention products, both of which the majority of respondents had never used. More than half of the respondents agreed that providing either the Bath Wipes or the Keep Dri dressing to patients to assist with their hygiene needs between dialysis sessions would be both acceptable and feasible. Even though the nurse respondents were least familiar with the waterproof cover, it was rated overall as more acceptable ( $81 \%)$ and feasible (70\%) than the bath wipes (61\% and 51\%, respectively) (Refer to Table 1 ). Median and mode for all responses was "Agree".

[Insert Table 1 approximately here] 
Nurses identified many benefits of using the Bath Wipes between dialysis sessions. The most frequently identified benefit was that the patients did not have to take either a bath or a shower, both of which potentially led to wet dressings and infections. Thus, the use of the wipes would be a safe strategy to reduce infections and therefore more cost effective than treating infections after they occurred. It was indicated that the wipes might be an easy option for those patients who currently have difficulty meeting personal hygiene needs, with a subsequent improvement of their self-esteem, or that it would reduce the likelihood of patients forgetting about the need to keep their dressings dry because they would not be standing in the shower. Using the wipes would negate the need to try and cover the dressing with plastic and tape, advice that some respondents gave to patients. The wipes were perceived as beneficial particularly for non-ambulatory patients.

With respect to the question about barriers to patients using the Bath Wipes between dialysis sessions, the continued availability of the products and ongoing costs were potential barriers noted by some nurses. The nurses did not know if the product would be as refreshing as having a shower or bath in the tropical climate, or whether the patients would feel as clean after using the wipes compared to after having a shower. Practical aspects such as whether the eight wipes included in each pack would be adequate for some of the larger patients, whether the patients might feel cold when using them, and disposal of the used wipes, were noted as potential barriers to their use. Also, the Bath Wipes do not address how patients can wash their hair, which they may usually do in the shower.

The nurses were asked about the benefits of the Keep Dri dressings. The opportunity for patients to shower safely, thus keeping their dressing dry and intact, was overwhelmingly the major benefit of this product, with all nurses noting such benefits. One nurse commented that the provision of a waterproof cover for the dressing would be less suggestive to patients that there was any deficit in their personal hygiene and would respect patients' preference for traditional methods of attending to their personal hygiene (showering or bathing) rather than using wipes.

There were some very practical responses to the question about barriers to patients using the Keep Dri dressing. These included: patients may have difficulty applying the waterproof cover, or forget to use it before they get into the shower, which could lead to the exit site getting wet; patients may not remove it after showering, which may lead to accumulation of moisture around the exit site; the dressing may not adhere to "hairy men"; some patients may be allergic to the product; concerns that it may not suit femoral catheters, or that it may give the patient a false sense of security when bathing, or that the patients may believe that they could go swimming with this cover in place. Another concern was that patients may accidentally remove the exit site dressing at the same time as removing the waterproof cover, which would leave the CVC exit site exposed. There were also a couple of concerns voiced about the ongoing cost, continuity of supply and waste disposal of the product.

\section{Phase Two}

Phase Two of the study consisted of conversational interviews with all 27 patients with a CVC in place. They were asked about their usual hygiene practices and routines at home, ways they tried to keep their 
dressing dry while bathing or showering, and whether those strategies were successful. They were then shown the two products and discussed if they thought these would be helpful for them.

Usual hygiene practices varied from showering independently $(n=22)$, showering with assistance $(n=3)$, taking a bath as per instructions provided to them $(n=1)$, or taking a 'bird bath' rather than a shower or bath $(n=2)$. The phrase 'bird bath' is a local colloquialism and refers to sitting or standing at a sink and then selectively splashing water on parts of the body, or using a wet and/or soapy washcloth/face flannel to do so.

Some of the patients detailed quite elaborate and time-consuming actions they took to try and keep their dressings dry. One patient who covered her dressing with a towel folded in threes to try and keep it dry (often unsuccessfully) when she showered every second day, was non-committal about trying the bath wipes but was highly motivated to start using the waterproof cover immediately. Another patient saw the benefit of the waterproof cover because she "struggles with keeping the dressing dry", despite taking a lot of care when using a hand-held shower. This patient, although not as keen to try the bath wipes, had seen them previously in hospital and felt they would potentially be useful on days she didn't shower. Another patient thought the wipes felt thick and they could perhaps be used in place of one of her twice-daily showers. One patient, who patted his dressing dry if it got wet even after he tried to avoid the area around the catheter by using a hand-held shower, was adamant that the wipes "wouldn't clean him" but was very motivated to try the waterproof cover. He even hoped he could swim with the cover, which echoed some nurses' concerns from phase 1, that patients may try to use the covers for more than they are intended. Another respondent said he changed the dressing when it got wet. This same patient showed some interest in trying the waterproof cover, but he was not interested in trying the bath wipes.

Keeping dressings dry was not always possible, even when the showering was led by care staff who should have been competent to do so. For example, one patient said, "The staff shower me but get it [the dressing] wet. I get worried and ask them to cover it". Even though the nurse-in-charge at the facility put up a sign to keep the dressing dry, and the staff covered it in plastic, it still got wet. However, a nonGovernment organisation providing care to one of the other patients with a femoral exit site used a larger size of the same brand of waterproof cover, and the patient was reluctant to use anything else because what they were doing was effective in keeping the CVC dressing dry. He said he was interested in trialling the bath wipes on the days when his carer did not shower him.

Generally, patients expressed a preference for showering and feeling the water run over them. For example, the patient with a femoral dressing who tried to shower herself twice a day under a fixed shower head thought the cover "would be better and easier than [plastic] wrap" but was not so keen on trying the bath wipes because she said she would always prefer a shower. Some patients raised concerns, however, about their capability of using the waterproof cover. For example, one patient who showered herself but had someone in the house in case she should fall, said, "If I put it [the cover] over that [the dressing] I might peel the whole thing off". This echoed a concern of the researchers, and one of the inclusion criteria for participants in the third phase of the study having the manual dexterity to apply and remove 
the cover. A younger patient who "likes the water running over [her] skin" was willing to try the bath wipes. But she was also keen to try the waterproof cover, saying it "might cover the lines too so they don't get wet - good". This lady said she was capable of sticking the waterproof cover onto her skin. Another lady said that although the wipes felt nice on her hands, she would continue with having a shower and did not wish to change her hygiene routines. Yet another lady was very excited at the possibility of using the waterproof cover, saying, "at last I can have a shower without a garbage bag on". The two women who had a 'bird' bath/sponge had slightly different responses to the options offered to try. One was not that interested in the wipes, but was extremely happy to think that she could shower again by using the waterproof cover. The other was willing to try the bath wipes and seemed to like that they can be warmed. But her eyes 'lit up' when shown the waterproof cover and said that her daughter or husband could help stick it on because "showers are better, cleaner".

\section{Phase Three}

Twenty-two patients were recruited to this phase commencing mid-January 2019 , with data collection completed end-July 2019. Eleven other patients were assessed as not eligible to participate (reasons included cognitive decline, medically unstable), and one patient withdrew after consenting before data collection began. Participants were provided with the product/s of their choice as they attended dialysis (either twice weekly or three times per week) over a six-week period. Each dialysis session the treating nurse inspected the dressing and exit site, and at least once per week a researcher talked with the participants about their experiences with the products, how they attended to their hygiene, and whether the dressings remained dry.

Exit site dressings were intact on all sides $236 / 283$ (83.4\%) of the completed audits. Only $16 / 312(5.1 \%)$ dressings were wet at the time of dialysis; however, 29/299 (9.7\%) dressings were assessed as having been wet between dialysis sessions but were dry by the time of dialysis. The Keep Dri dressing covers were most popular, and most frequently used, being supplied 247 times compared to 120 times for the Bath Wipes. No participants had an infected CVC site or line while using the products. There is some missing data related to either patients not attending all of their scheduled dialysis sessions or incomplete data collection forms.

In this phase, participants described how they experimented with the products, particularly with the Keep Dri. A 52-year old woman said the dressing covers were fine once she used tape to reinforce the edges. A 48-year old woman said that the Keep Dri dressings were "fantastic" and showering was "less stressful" although sometimes they came unstuck when she raised her arms. A 44-year old man admitted how he pushed the boundaries to find out how long the Keep Dri dressing would stay intact under a hot shower he found it started to lift after 10 minutes. Sometimes participants needed assistance to apply the Keep Dri but once it was in place showering was much easier. Sometimes the patients forgot to use it, whilst a middle-aged man said that it was a little time-consuming putting the waterproof dressing on so sometimes he would not use it. 
Participants who used the bath wipes commented that they felt clean and refreshed. Not needing assistance to use the bath wipes was a positive experience for several participants, and they chose them over the waterproof dressing cover so that they could be independent.

Examples of four patients' experiences are now presented. A 52-year old woman who lives in the city with family support told the researcher in Phase 2 that she had a bird bath to ensure she kept her dressing dry. She used both products during Phase 3, and said that the Keep Dri was better and loved being able to shower again. It made her feel good, and she was smiling when talking about her experiences; her son corroborated his mother's preference for the waterproof cover. Her CVC dressing was dry and fully intact at $100 \%$ of the audits, even though she occasionally missed a dialysis session (which meant that her dressing needed to remain in situ for longer).

A 79-year old woman told the researcher in Phase 2 that she used a hand shower, every second day, with a towel folded in threes over the exit site dressing to try and keep it dry. She used and liked both options over the six weeks in Phase 3. She found the bath wipes easier to use, saying that she sometimes found it difficult to remove the waterproof dressing cover from her "thin skin". However, using the Keep Dri was "terrific, you can use both hands". She loved being able to wash her hair with both hands, and was happy that she could wash under her right armpit (the side her catheter was located). Her CVC dressing was dry and fully intact at $100 \%$ of her dialysis sessions.

A 59-year old man who did not participate in Phase 2, used only the Keep Dri in Phase 3. He felt clean after his daily shower and said that the Keep Dri sealed well on his hairy chest, without giving him a "wax" when removed. The CVC dressing, however, was fully intact at only $3 / 11(27 \%)$ of his dialysis sessions, most likely due to diaphoresis. It was wet at only one dialysis session though, so he managed to protect his exit site reasonably well.

A 58-year old woman with limited vision reported in Phase 2 that the dressing got wet when she showered every second day, which she would then pat dry with a towel. She was eager to trial the Keep Dri and she hoped that this approach would minimise the itching associated with a wet exit site dressing. Although she needed a little help from her carer to apply and remove the Keep Dri because of her poor eyesight, she felt "more confident in the shower" and more independent. She commented "they are deadly", which is a positive expression of Australian Indigenous persons. During Phase 3, her dressings were intact 16/18 $(89 \%)$ of the audits, were always dry at the time of the audit, but appeared as though they had been wet on $2 / 18(11 \%)$ occasions, which was a definite improvement on her usual situation.

\section{Discussion}

There was a satisfactory level of participation in all three phases of the study. Most of the nurse respondents found the options both acceptable and feasible in principle. The nurses identified that patients' hygiene preferences and practices were rarely discussed in detail. The patients were eager to be involved, with their responses indicating that they were aware of the ideal being to keep their dressing dry and intact between dialysis sessions. They described detailed, personalised and quite inventive strategies 
for trying to meet that goal. The participants responded positively to being given a choice and being able to attend to their hygiene safely, and according to their preferences. Their willingness to use the options in Phase 3 was reflected in the high participation rate, and in their disappointment that once their six-week trial of the products had finished they had to revert to earlier less-effective strategies to care for their dressings.

The participants' preferences for showering over bath wipes is consistent with research with other hospitalised patients (17). In summary, the patients welcomed the opportunity to shower afforded by the waterproof dressing cover. The possibility voiced by some nurses that patients might push the boundaries, however, was realised by a couple of patients who tested how long they could remain in the shower before the dressing integrity was breached.

The results of this study resonated with the components of the COM-B system for understanding behaviour and behaviour change (13). The opportunity to change was presented by the securing of two products that were previously not used in the Renal Service. Each product had features that appealed to the individual participants. The option of safely showering reduced any dissonance between the advice previously provided to patients that having a bath was the best option, yet most patients were unable to comply with that option as they did not have a bathtub in their homes. Nurses should be able to provide appropriate education for patients to use Bath Wipes and Keep Dri waterproof dressing options safely in the future. After minimal instruction, patients demonstrated their capability to use the products. Nurses can be reassured by the patient participants' responses that indicated their motivation to keep their CVC dressings dry and intact. Motivation to make a change in behaviour was evident by enthusiastic participation in this study, and continued desire to have access to the products of their choice.

There are some aspects associated with using these options that the organisation needs to resolve. Both products generate additional rubbish to be disposed of, an environmental concern to all. Patients can purchase on-line the Bath in Bed wipes but will pay a little more than it costs the health service. This additional cost will be a challenge to some of our patient cohort, many of whom are in a low socioeconomic status bracket. It is even more difficult and costly for individuals to purchase the waterproof dressing cover. However, patients clearly preferred this product and embraced being able to shower without damaging their exit site dressing. Additionally, there are several dermatological changes associated with end-stage renal disease such as pruritis, xerosis, decreased cutaneous blood flow leading to impaired wound healing (18). We cannot attest to the safety of other brands of bath wipe products on the fragile skin of patients undergoing haemodialysis for end-stage renal disease.

\section{$\underline{\text { Strengths and limitations }}$}

This study explored a topic about which little was known, preferences of patients with CVCs about their personal hygiene in a tropical climate. There was minimal burden for those participants who participated in the study, other than providing feedback about the use of the hygiene options. It is acknowledged that the observation nature of study design was not developed with infection as an outcome of interest and the low level of infections during this study needs to be interpreted with caution. It is not possible to 
generalise to other participant groups. Similarly, since the study design allowed for participants to choose what products they used, and how often they used them, it was not possible to compare dressing intactness and wetness rates according to the two products provided.

\section{Conclusion}

The heat and high humidity of this tropical region will continue to pose challenges to maintaining the integrity of an occlusive dressing and preventing sepsis. However, the provision of options to enable patients to keep their dressings dry and intact while they attended to their personal hygiene as they wished, filled an unmet need and promoted patient dignity and autonomy. It is possible for nurses to provide solutions for some of the potential barriers. There was enthusiastic participation in the study, even by some patients who are traditionally somewhat reluctant to engage in conversations, reflective of incorporating the core values underlying research with Aboriginal and Torres Strait Islander Peoples. For some patients, it has increased their willingness to take a more active role in their dressing care, and nurses are integral to supporting these opportunities and efforts. Further studies will be designed to assist those patients to achieve those goals. Funding for ongoing provision of the products needs to be considered by the Renal Service. However, monitoring of their use in a non-research environment will be required (for example, to guard against complacency on the part of patients and nurses). Other interventions that further increase patient participation in their own care warrant further investigation.

\section{Relevance to clinical practice}

This study demonstrated that relatively low-cost options were effective in increasing patients' involvement in their self-care, whilst maintaining the integrity of exit site dressings. The cost of such options is far less than the cost of a bacteraemia to the individual and organisation. It was a simple solution to remove one of the many lifestyle modifications faced by people on haemodialysis via a central line.

\section{Declarations}

\section{Ethical declarations}

a. The study protocol and associated documents were approved by the Townsville Hospital and Health Service Human Research Ethics Committee.

b. All methods were carried out in accordance with relevant guidelines and regulations.

c. Informed consent was obtained from all participants.

\section{Consent for publication}

All authors consent to manuscript publication.

Availability of data and materials 
The datasets generated and/or analysed during the current study are not publicly available related to participant information and consent but are available from the corresponding author on reasonable request.

\section{Conflict of interest statement:}

The authors have no conflict of interest to declare

Funding support:

Townsville Hospital and Health Service Study, Education and Research Assistance Grant (SERTA2018_10, $\$ 29,502)$. The funder had no involvement in any part of the study (including data analysis) or writing of the manuscript.

\section{Authors' contributions}

All authors made substantial contributions to each of the criteria of authorship, as per the following:

\begin{tabular}{|llll|}
\hline $\begin{array}{l}\text { Wendy } \\
\text { Smyth }\end{array}$ & $\begin{array}{l}\text { Conception and design, acquisition of data, } \\
\text { analysis and interpretation of data }\end{array}$ & $\begin{array}{l}\text { Drafting and } \\
\text { revising the } \\
\text { article }\end{array}$ & $\begin{array}{l}\text { Final approval of } \\
\text { submitted version }\end{array}$ \\
\hline $\begin{array}{l}\text { Joleen } \\
\text { McArdle }\end{array}$ & $\begin{array}{l}\text { Conception and design, acquisition of data, } \\
\text { analysis and interpretation of data }\end{array}$ & $\begin{array}{l}\text { Drafting and } \\
\text { revising the } \\
\text { article }\end{array}$ & $\begin{array}{l}\text { Final approval of } \\
\text { submitted version }\end{array}$ \\
\hline $\begin{array}{l}\text { Kristin } \\
\text { Wicking }\end{array}$ & $\begin{array}{l}\text { Conception and design, acquisition of data, } \\
\text { analysis and interpretation of data }\end{array}$ & $\begin{array}{l}\text { Drafting and } \\
\text { revising the } \\
\text { article }\end{array}$ & $\begin{array}{l}\text { Final approval of } \\
\text { submitted version }\end{array}$ \\
\hline $\begin{array}{l}\text { Kimberley } \\
\text { Quayle }\end{array}$ & $\begin{array}{l}\text { Acquisition of data, ongoing conduct of the } \\
\text { study, analysis and interpretation of data }\end{array}$ & $\begin{array}{l}\text { Drafting and } \\
\text { revising the } \\
\text { article }\end{array}$ & $\begin{array}{l}\text { Final approval of } \\
\text { submitted version }\end{array}$ \\
\hline $\begin{array}{l}\text { Cate } \\
\text { Nagle }\end{array}$ & $\begin{array}{l}\text { Conception and design, analysis and } \\
\text { interpretation of data }\end{array}$ & $\begin{array}{l}\text { Drafting and } \\
\text { revising the } \\
\text { article }\end{array}$ & $\begin{array}{l}\text { Final approval of } \\
\text { submitted version }\end{array}$ \\
\hline
\end{tabular}

\section{Acknowledgements}

Ms Kim Hughes was a Principal Investigator but has since retired. We acknowledge her input into the conception and design of the study, acquisition of data, interpretation of the findings, and input into previous drafts of the manuscript. This study would not have proceeded without the efforts of all nurses of the Townsville Renal Service, who were instrumental in collecting data, providing the products to the patients as per their preferences/requests, and interacting with patients about their experiences.

\section{References}


1. Murray MA, Thomas A, Wald R, Marticorena R, Donnelly S, Jeffs L. Are you SURE about your vascular access? Exploring factors influencing vascular access decisions with chronic hemodialysis patients and their nurses. The CANNT Journal. 2016;26(2):21-8.

2. Australian Institute of Health and Welfare. Staphylococcus aureus bacteraemia in Australian hospitals 2016-17: Australian hospital statistics. Health services series no. 83. Cat. no. HSE 198. Canberra, Australia: AlHW; 2017.

3. Australia and New Zealand Dialysis and Transplant Registry. Chapter 3: Mortality in end stage kidney disease. 2019. In: ANZDATA Registry 42nd Report [Internet]. Adelaide, Australia: Australia and New Zealand Dialysis and Transplant Registry. Available from: http://www.anzdata.org.au.

4. Cai Y, Zhu M, Sun W, Cao X, Wu H. Study on the cost attibutable to central venous catheter-related bloodstream infection and its influencing factors in a tertiary hospital in China. Health and Quality of Life Outcomes [Internet]. 2018; 16(198).

5. Hill KE, Barbara J, Thorburn L, Torpey K. The long-term use of a tunnelled central venous catheter for haemodialysis. Renal Society of Australasia Journal. 2013;9(3):126-8.

6. McArdle J, Smyth W, Wicking K, Gardner A. Haemodialysis central venous catheter exit site dressings in the tropics: a crossover randomized controlled trial. Wound Practice \& Research. 2017;25(4):2007.

7. Smyth W, McArdle J, Gardner A. Central venous catheter exit site dressings: Balancing patients' needs, nurses' experiences and the research evidence. Wound Practice and Research. 2016;24(1):416.

8. XXXX [name to be supplied] Renal Services. Caring for your vascath/permcath. Townsville, Queensland, Australia: Queensland Health; 2011.

9. Wong D, Walker D, Cove J, Pires-Yfantouda R. Supporting patients better on self-care haemodialysis: a survey. Journal of Renal Nursing. 2015;7(2):64-72.

10. Hughes K, Gardner A, McArdle J. Audit of factors associated with the intactness of central venous catheter exit site dressings for northern Australian haemodialysis patients. Renal Society of Australasia Journal. 2011;7(3):108-14.

11. Heale R, Twycross A. What is a case study? Evidence Based Nursing. 2018;21(1):7-8.

12. Yin RK. Case study research. Design and methods. 2nd ed. Thousand Oaks: SAGE; 1994.

13. Michie S, van Stralen MM, West R. The behaviour change wheel: A new method for characterising and designing behaviour change interventions. Implementation Science. 2011;6(1):42.

14. Bessarab D, Ng'andu B. Yarning about yarning as a legitimate method in Indigenous Research. International Journal of Critical Indigenous Studies. 2010;3:37-50.

15. Elo $\mathrm{S}$, Kyngäs $\mathrm{H}$. The qualitative content analysis process. Journal of Advanced Nursing. 2008;62(1):107-15.

16. National Health and Medical Research Council. Ethical conduct in research with Aboriginal and Torres Strait Islander Peoples and communities: Guidelines for researchers and stakeholders. 
Canberra, Australia: Commonwealth of Australia; 2018.

17. Veje PL, Chen M, Jensen CS, Sørensen J, Primdahl J. Bed bath with soap and water or disposable wet wipes: Patients' experiences and preferences. Journal of Clinical Nursing. 2019;28(1112):2235-44.

18. Avermaete A, Altmeyer P, Bacharach-Buhles M. Skin changes in dialysis patients: A review. Nephrology Dialysis Transplantation. 2001;16(12):2293-6.

\section{Tables}

Table 1: Acceptability and feasibility ratings of the two products

\begin{tabular}{|c|c|c|c|c|c|}
\hline & $\begin{array}{l}\text { Strongly } \\
\text { Agree }\end{array}$ & Agree & Unsure & Disagree & $\begin{array}{l}\text { Strongly } \\
\text { Disagree }\end{array}$ \\
\hline \multicolumn{6}{|l|}{ Acceptability of interventions: } \\
\hline $\begin{array}{l}\text { It would be acceptable to provide Bath in } \\
\text { Bed Wipes to renal patients as a way to } \\
\text { meet their hygiene needs between dialysis } \\
\text { sessions ( } n=36)\end{array}$ & $5(14 \%)$ & $\begin{array}{l}17 \\
(476 \%)\end{array}$ & $\begin{array}{l}7 \\
(19 \%)\end{array}$ & $4(11 \%)$ & $3(8 \%)$ \\
\hline $\begin{array}{l}\text { It would be acceptable to provide Keep Dri } \\
\text { dressing to renal patients as a way to meet } \\
\text { their hygiene needs between dialysis } \\
\text { sessions } \\
(n=37)\end{array}$ & $\begin{array}{l}11 \\
(30 \%)\end{array}$ & $\begin{array}{l}19 \\
(51 \%)\end{array}$ & $\begin{array}{l}6 \\
(16 \%)\end{array}$ & $0(0 \%)$ & $1(3 \%)$ \\
\hline \multicolumn{6}{|l|}{ Feasibility of interventions: } \\
\hline $\begin{array}{l}\text { It would be feasible to provide Bath in Bed } \\
\text { Wipes to renal patients as a way to meet } \\
\text { their hygiene needs between dialysis } \\
\text { sessions ( } n=37 \text { ) }\end{array}$ & $2(5 \%)$ & $17(46 \%)$ & $\begin{array}{l}11 \\
(30 \%)\end{array}$ & $4(11 \%)$ & $3(8 \%)$ \\
\hline $\begin{array}{l}\text { It would be feasible to provide Keep Dri } \\
\text { dressing to renal patients as a way to meet } \\
\text { their hygiene needs between dialysis } \\
\text { sessions }(n=37)\end{array}$ & 7 (19\%) & $\begin{array}{l}19 \\
(51 \%)\end{array}$ & $\begin{array}{l}10 \\
(27 \%)\end{array}$ & $0(0 \%)$ & $1(3 \%)$ \\
\hline
\end{tabular}

